\title{
From global to national scenarios: Bridging different models to explore power generation decarbonisation based on insights from socio-technical transition case studies
}

\author{
Andries F. Hof ${ }^{\mathrm{a}, \mathrm{b}, *}$, Samuel Carrara ${ }^{\mathrm{c}, \mathrm{d}}$, Enrica De Cian ${ }^{\mathrm{e}, \mathrm{f}}$, Benjamin Pfluger $^{\mathrm{g}}$, \\ Mariësse A.E. van Sluisveld ${ }^{\mathrm{a}, \mathrm{b}}$, Harmen Sytze de Boer ${ }^{\mathrm{a}}$, Detlef P. van Vuuren ${ }^{\mathrm{a}, \mathrm{b}}$ \\ ${ }^{a}$ PBL Netherlands Environmental Assessment Agency, The Hague, Netherlands \\ ${ }^{\mathrm{b}}$ Copernicus Institute of Sustainable Development, Utrecht University, Utrecht, The Netherlands \\ ${ }^{\mathrm{c}}$ Fondazione Eni Enrico Mattei (FEEM), Milan, Italy \\ ${ }^{\mathrm{d}}$ Renewable and Appropriate Energy Laboratory (RAEL) and Energy and Resources Group (ERG), University of California, Berkeley, United States \\ ${ }^{\mathrm{e}} \mathrm{Ca}$ ' Foscari Unversity of Venice, Venice, Italy \\ ${ }^{\mathrm{f}}$ Fondazione Centro Euro-Mediterraneo sui Cambiamenti Climatici (CMCC), Venice, Italy \\ ${ }^{\mathrm{g}}$ Fraunhofer Institute for Systems and Innovation Research ISI, Karlsruhe, Germany
}

\section{A R T I C L E I N F O}

\section{Keywords:}

Integrated assessment

Socio-technical transitions

Multi-level perspective

IAM

Climate change

Scenarios

\begin{abstract}
A B S T R A C T
In this paper, we apply two global Integrated Assessment Models (IAMs) and one detailed European electricity system model to explore the consequences of different narrative-based low-carbon scenarios on the electricity system from the global to national scale. The narratives are based on insights from socio-technical transition analysis on niche-innovations. The main aim of this exercise is to examine the solution space in low-carbon scenarios for electricity supply from the global to national scale, which is largely neglected when focusing on cost-optimal solutions only. We show that taking into account insights from socio-technical transition analysis can have large impacts on the projected transition strategy, especially regarding relatively costly technologies that currently have a high momentum. For instance, we find that the share of offshore wind in electricity generation in Europe is less than $3 \%$ or up to $27 \%$ by 2050 , depending on the underlying narrative. These ranges are useful input for policy-makers, as they show the degree of flexibility in mitigation options. Furthermore, our analysis shows that combining IAMs with more detailed sectoral models illuminates the challenges on a more detailed geographical scale, for instance regarding storage requirements and the need for interconnectivity across European borders.
\end{abstract}

\section{Introduction}

Many national (Danish Energy Agency, 2014; Grandjean et al., 2014; McGlade et al., 2016; Öko-Institut and ISI, 2016), regional (European Commission, 2011), and global (Clarke et al., 2014; Kriegler et al., 2014; van Vuuren et al., 2011; Weyant et al., 2013) scenarios to low-carbon economies have been developed to explore mitigation strategies that would achieve the long-term climate targets as agreed in the Paris Agreement (UNFCCC, 2015). These scenarios have been developed using computational modelling, adopting, amongst others, Integrated Assessment Models (IAMs) and dedicated energy models. IAMs use high levels of aggregation (such as large world regions) and provide a global analytical understanding of transitions, climate change, and the various complex interlinkages between the
Earth and human system. In their conceptualisation of global systems change, IAMs necessarily focus on aggregated universal processes. The dedicated models are used for more detailed analyses on sector-level or for lower geographical scales, such as on country-level (Deane et al., 2012). While these models have a higher temporal and spatial resolution compared to IAMs, they mostly lack information on developments in the rest of the world or in other sectors that may influence the sector under investigation. As such, global models depict a coherent and consistent picture of system change on a wider spatial scale which leads to more abstraction, whereas dedicated energy models contain a specific focus area. This implies that for the second type of models, assumptions have to be made regarding variables such as fuel prices, biomass availability, and electricity demand, which depend on developments in other sectors or regions that are beyond the scope of the

\footnotetext{
* Corresponding author.

E-mail address: andries.hof@pbl.nl (A.F. Hof).
} 
model itself and scenario-dependant. As global IAMs can provide information on such variables, it creates an opportunity to combine these two types of models in a harmonised framework.

There are numerous examples of such linkages between global and regional or sectoral models. For instance, Deane et al. (2012) link an energy system model to a power system model to improve the understanding of the energy systems model results regarding the Republic of Ireland's electricity sector. Collins et al. (2017) carry out a similar, but methodologically wider investigation focused on the modelling of the system integration of variable renewable energy (VRE) into the EU power system. Drouet et al. (2005) developed a scenario for the residential sector in Switzerland using a combined model, where the residential sector is described by a bottom-up sector-specific model and the rest of the economy by a computable general equilibrium model. Deetman et al. (2015) have linked a global IAM with a European power system model, analysing a predefined selection of mitigation measures. Similarly, the global energy model POLES (Després et al., 2017) has been used in conjunction with the more detailed European energy model PRIMES (E3MLab, 2016) since the mid-1990s (Capros et al., 1998). In the European FP6 project ADAM, several bottom-up and topdown models were linked to develop $2{ }^{\circ} \mathrm{C}$ scenarios for Europe (Jochem and Schade, 2009).

However, all the above studies, with the exception of Deetman et al. (2015), focus on cost-optimal scenarios only. This restriction ignores real-world imperfections (Staub-Kaminski et al., 2014) and has been shown to not approximate real-world transitions (Trutnevyte, 2016). Moreover, it ignores the possible diversity in lowcarbon strategies. One method to gain insight into such flexibility is by way of uncertainty analysis, such as done by Li and Trutnevyte (2017). However, for complex global IAMs and detailed dedicated models used in our analysis, common uncertainty analysis approaches such as Monte Carlo are not viable due to their computational requirements. ${ }^{1}$ Therefore, in this paper we apply an alternative method to test the diversity in transition dynamics by developing scenarios based on narratives or storylines. As shown by Trutnevyte et al. (2014), combining qualitative storylines with quantitative modelling has several advantages: it may lead to novel and creative ways of thinking about the future, it may help communicating the results of scenario analyses, and it allows a much broader picture by including governance aspects. Earlier work (e.g., Deetman et al., 2015) has adopted a similar approach but with more ad-hoc assumptions.

In the current study, we develop two contrasting scenarios empirically underpinned by sociotechnical transition case studies. The quantitative scenarios mainly focus on technology developments, whereas socio-technical transitions also focus on changes in consumer practices, policies, cultural meanings, infrastructures, and business models (Geels, 2019). The framework used to analyse socio-technical transitions is the Multi-Level Perspective (MLP; Geels, 2002). The MLP is a widely used social science approach for analysing socio-technical transitions on three levels: niche-innovations, socio-technical regimes, and macro landscape pressures (Geels, 2002; Geels et al., this issue, Geels and Schot, 2007). We applied the method by van Sluisveld et al. (this issue) to align the MLP with the quantitative scenarios.

To our knowledge, there are no studies available that analyse narrative-based quantitative decarbonisation scenarios limiting global $\mathrm{CO}_{2}$ emissions to a certain budget or level using a combined set of models from the global to national scale. We focus on changes in the electricity sector as this sector is currently responsible for $25 \%$ of global greenhouse gas emissions, which is more than any other sector, and literature shows that the largest reduction potential is projected in electricity

\footnotetext{
${ }^{1}$ Both IMAGE and WITCH contain a lot of technological detail and have hundreds of different input and output variables. While in theory, a light version of these models could be developed, this would take a lot of effort and will necessarily provide less detailed output.
}

supply (IPCC, 2014).

The modelling set included in our analysis consists of two global IAMs as well as one European country-level electricity model. The two IAMs include IMAGE (Integrated Model to Assess the Global Environment, Stehfest et al., 2014) and WITCH (World Induced Technical Change Hybrid, Emmerling et al., 2016). We contrast the global results with results from the Enertile model (formerly known as PowerACE; Pfluger, 2014),$^{2}$ offering consistent national perspectives in a European context.

The main aim of this exercise is to gain insight in the solution space in low-carbon scenarios for electricity supply from the global to national scale, by defining storylines that take into account social preferences as deducted from MLP case studies on niche-innovations. Furthermore, our modelling exercise is an important step in the eightstep methodological procedure to develop socio-technical scenarios as set out by Geels et al. (this issue). As such, the quantitative scenarios form the basis to identify transition bottlenecks and to formulate policy recommendations.

The paper is structured as follows. Section 2 provides the theoretical basis on which the MLP case studies were used to create alternative scenarios and an overview of the models and how they were linked. Section 3 discusses the results of the scenarios from a global to European and national level. Section 4 discusses how our exercise compares to previous exercises in which MLP was used to develop scenarios and summarizes the main conclusions.

\section{Method}

This section provides a short methodological overview of how the MLP was aligned with scenario development (Section 2.1), a description of the models used and how they were linked (Section 2.2), the overall scenario storylines (Section 2.3), an explanation of how the qualitative storylines were implemented in the quantitative scenarios (Section 2.4).

\subsection{Aligning the MLP with scenario development}

For a detailed theoretical grounding of how the MLP is aligned with scenario modelling, we refer to van Sluisveld et al. (this issue) and Section 3 of Geels et al. (this issue). Here, we summarise the theory based on which the alignment was done.

The MLP and scenario modelling differ fundamentally in their assessment approach (narrative-based vs. quantitative assessment) and analytical focus (emergent and disorderly developments vs. stylised gradual transitions). Yet, both approaches share two important concepts that provide the basis for potential alignment. These are i) momentum (departure from status-quo) and inertia (stability and robustness of a regime to maintain itself), and ii) transition narratives.

The MLP applies the concepts of momentum and inertia to explain the degree to which systemic change has materialised. The analytical emphasis hereby is on qualitative elements such as power struggles, networks and coalitions, and processes across multiple dimensions (e.g. social, technical, economic, political, and cultural). Scenario modelling applies these concepts to illustrate the rate of change for various, more general, quantitative indicators using learning rates and growth curves. Hence, in most quantitative models the formal description of processes is just a means to an end, i.e. model outcomes.

Both approaches use transition narratives as a pragmatic research instrument to describe change, though each with a different purpose. The MLP uses narratives to explain interactions between niches, regimes and landscapes. Given the qualitative nature of the concepts addressed in the MLP, narratives offer the opportunity to detect generic

\footnotetext{
${ }^{2}$ For a documentation of IMAGE, see http://themasites.pbl.nl/models/image; for WITCH http://www.witchmodel.org/ and for Enertile www.enertile.eu.
} 
patterns that result from interactions between actors (Geels and Schot, 2007). Scenario modelling uses narratives as context for parameterisation of relevant inputs and assumptions. As social systems find no direct analogue in quantitative models (De Cian et al., this issue), scenario narratives are used to apply alternative assumptions on for instance the speed of adoption of certain technologies.

MLP provides a wealth of information on the driving forces of sociotechnical transitions, which can be used to inform scenario modelling on recent and emerging developments for a wide range of niche-innovations. We have done so by using the MLP to draw out two contrasting storylines on actor positioning and momentum of change for several technological and social niche-innovations that can function as an analytical bridge between both scientific approaches (see Section 2.3).

These storylines are then translated into quantitative scenarios for scenario modelling (see Section 2.4). This is done by drawing insights from MLP case studies of social and technological niche-innovations and using this information in scenario modelling. The niche-innovations have been analysed across three analytical dimensions: (1) innovation and market trajectories (techno-economic assessment), (2) actors and social networks (socio-cognitive assessment), and (3) the governance and policies over the last 10-15 years. The assessment as a whole allowed drawing an overall qualitative judgement of the current momentum of each niche-innovation, which is assumed to provide some indication of the potential towards the near future.

\subsection{Models and model interlinkages}

The IMAGE integrated assessment modelling framework (Bouwman et al., 2006; Stehfest et al., 2014) focuses on the chain of global environmental change for both climate and land use. Important inputs into the system are assumptions on population and economic development. The model describes the investments in and use of different types of energy options influenced by technology development (learning-by-doing) and resource depletion. Inputs to the model are macro-economic scenarios and assumptions on technology development, preference levels and restrictions to fuel trade. Emissions from land-use changes, natural ecosystems and agricultural production systems, and the exchange of carbon dioxide between terrestrial ecosystems and the atmosphere are also simulated. The climate model MAGICC (Meinshausen et al., 2011) is used to project the future climate. World countries are grouped into 26 regions. Europe is represented by two sub-regions: Western Europe and Central Europe. Together, these regions represent the EU-28 and Albania, Bosnia and Herzegovina, Iceland, Liechtenstein, Macedonia, Norway, Serbia and Montenegro, and Switzerland.

WITCH (Bosetti et al., 2006; De Cian et al., 2012; De Cian and Tavoni, 2012; Emmerling et al., 2016) is a hybrid model which combines an inter-temporal optimal growth model (able to capture the long term economic growth dynamics) with a detailed representation of the energy sector. The latter is fully integrated (hard-linked) with the rest of the economy so that energy investments and resources are chosen optimally, along with the other macroeconomic variables. Land use mitigation is modelled through a land use and forestry model (GLOBIOM, Havlík et al. 2014), soft-linked to the main model. The same climate model as IMAGE is used (MAGICC). Investments include investments in the aggregate capital as well as investments in power technologies, in light duty and road freight vehicles, and in R\&D. Both innovation and diffusion processes are endogenously modelled. In particular, international spillovers of knowledge are considered in order to model the exchange of knowledge across countries. World countries are grouped into 13 regions. Europe is divided between Western Europe (the pre2004 EU 15 countries + the EFTA countries ${ }^{3}$ ) and Central Europe (the

\footnotetext{
${ }^{3}$ Switzerland, Norway, Iceland, and Liechtenstein
}

13 countries that joined the European Union starting from 2004).

Enertile (derived from the model PowerACE; Pfluger, 2014) is a detailed bottom-up electricity system optimisation model. Enertile has detailed technical representations of the underlying processes in the power sector. The model optimises electricity supply to meet the demand of the included countries. For long-term analyses up to 2050, the model endogenously determines the capacity expansion and utilisation of conventional and renewable electricity generation technologies, transmission grids and storage facilities. Enertile utilises hourly weather data, which allows depicting the interdependencies between VRE technologies and meteorology. For a comprehensive representation of renewable electricity generation technologies, the model performs a detailed potential analysis, determining detailed potentials on a $7 \times 7 \mathrm{~km}$ grid in all of Europe. Enertile represents all EU countries as well as Norway and Switzerland. Representation of Northern African and Middle Eastern countries is optional but not included in this analysis.

Table 1 provides an overview of the main characteristics of each of the models used in our analysis, showing that the European level is the "meeting point" between the two groups of models adopted in this work, i.e. the two global IAMs (IMAGE and WITCH) and the European detailed power system model Enertile. More precisely, at the European level the Enertile scenarios adopted annual electricity demand, fuel and $\mathrm{CO}_{2}$-prices, as well as biomass use and hydro generation as exogenous input from IMAGE output. We have not harmonized electricity demand between IMAGE and WITCH, as we are mainly interested in differences in the energy mix between the scenarios and models instead of the absolute generation capacities.

In order to ensure a comparable level of decarbonisation, an additional restriction was introduced in Enertile capping the emissions in 2050 at the values concluded by the IAMs. Furthermore, Enertile was linked with IMAGE with respect to the share of biomass with Carbon Capture and Storage (BECCS) from 2020 onwards. The total European electricity demand in Enertile was broken down to national demands by assuming that the trend in demand is the same in each country. We have ensured consistency in socio-economic developments by assuming for all models that population and GDP follow the Shared Socioeconomic Pathway 2 (SSP2) trajectories (Dellink et al., 2017; Kc and Lutz, 2017). SSP2 can be regarded as the "middle of the road" scenario, where the demographic and socio-economic trends follow average historical patterns (O'Neill et al., 2014).

\subsection{Scenario storylines}

Two contrasting scenario storylines - Technological Substitution and Broader Regime Change - have been used, based on existing sociotechnical transition pathway typologies (Geels and Schot, 2007). The two storylines focus on a critical dimension of the future transition, i.e. the key actors that drive the transition towards a low-carbon society. Both are consistent with an $80 \%$ reduction in greenhouse gas emissions in 2050 compared to 1990 levels in the European Union (European Commission, 2011).

The Technological Substitution pathway is defined as a pathway in which currently dominant actors, such as large power utilities and existing car companies, play a key role in the transition towards a lowcarbon economy. As such, the objectives of EU sustainable development policies are achieved through incremental changes to the existing regimes (for example by adding CCS to fossil-fuelled power plants or by broadening the services of land owners) or adopting niche-innovations on a large scale (e.g. battery-electric vehicles, offshore wind power), without a fully re-ordering of societal structures. Technological Substitution is interpreted as a technological transition that exploits substitution in technical components, ensuring that the current business models and market structures can continue to exist. While the technical components of the socio-technical regime change in this pathway, regulative, normative, and cognitive institutional elements (e.g. user 
Table 1

Overview of model characteristics.

\begin{tabular}{|c|c|c|c|}
\hline & IMAGE & WITCH & Enertile \\
\hline Model classification & Integrated Assessment Model & Integrated Assessment Model & Electricity System Model \\
\hline Solution methodology & Recursive dynamic & Intertemporal optimisation & Intertemporal optimisation \\
\hline \multirow[t]{4}{*}{ Dynamic sector representation } & Power sector & Power sector & Power sector \\
\hline & Industry & Road transport & \\
\hline & Transport & & \\
\hline & Buildings & & \\
\hline Global resolution & Yes & Yes & No \\
\hline \multirow[t]{2}{*}{ European resolution } & 2 EU regions & 2 EU regions & 27 European countries \\
\hline & (Western Europe; Central Europe) & (Western Europe; Central Europe) & \\
\hline National resolution & No & No & Yes \\
\hline Time step & Annual & 5 years & Hourly \\
\hline \multirow[t]{3}{*}{ Technological resolution of power supply } & Power generation technologies & Power generation technologies & Power generation technologies \\
\hline & Generic storage technology & Transmission grids & Transmission grids \\
\hline & & Generic storage technology & Storage facilities \\
\hline
\end{tabular}

practices, lifestyles, governance arrangements) remain close to the existing regime.

In the Broader Regime Change pathway, the transition does not only involve a change in the technology configuration of the system, but also other aspects of the regime are assumed to change. This implies wider behavioural and cultural changes, new user practices and institutions. Incumbent industry actors may be overthrown by new entrants (e.g. households supplying electricity, e.g. via decentralised photovoltaics (PV)), or enter into new alliances with them. New coalitions in land use occur between farmers, retailers and consumers. There is also a greater role for social movements, civil society actors, and multi-level governance.

\subsection{Implementation of the storylines}

In all three models, the EU $80 \%$ reduction target is met by introducing a price on carbon which leads to a cost-optimal decarbonisation of the represented system - next to the specific interventions in the two storylines as described below. In the IAMs, a carbon price is implemented globally leading to the long-term target of limiting global temperature increase to $2^{\circ} \mathrm{C}$ with respect to the pre-industrial levels with a likely chance. ${ }^{4}$ As such, all three models used in this paper all have elements of cost optimisation, and therefore can only represent broader social, behavioural, and institutional changes in an implicit or an exogenous way (De Cian et al., this issue). We have selected MLP case studies of low-carbon niche-innovations over the past ten years in Germany (Rogge, 2015) and the UK (Geels et al., 2015) to translate storylines on actor positioning and momentum of change for several technological and social niche-innovations to quantitative scenarios. The UK and Germany were chosen as case study countries because their current transitions have strong overlaps with our Technological Substitution and Broader Regime Change pathway, respectively (Geels et al., 2016).

We have made a set of changes in specific model parameters in each of the two scenario storylines to develop scenarios that are consistent with the respective storyline, as summarised in Table 2. Such interventions can either be related to socio-behavioural, regulatory, or technical aspects, or involve more radical shifts in the system. The qualitative insights from the case studies need interpretation to feed into the quantitative structures in computational models, implying that the interpretations are tailor-made to the model given different modelling structures. Therefore, harmonisation between the models can occur on a high abstraction level (e.g. addressing common processes or representations across models). Nevertheless, for each of the models,

\footnotetext{
${ }^{4}$ In WITCH, such an optimised global carbon price would not achieve the $-80 \%$ target in Europe. Thus the carbon price is set at a higher level in Europe than in the rest of the world.
}

similar scenario interventions were made based on the case studies for the UK and Germany, as explained in more detail below.

Offshore wind was assessed as fitting best within a Technological Substitution transition dynamic, both in Germany and the UK. Despite its need for substantial governmental support, its momentum for further deployment was assessed as relatively high, as demonstrated by the UK. As this high momentum is in contrast with what cost-optimisation scenarios would project, an intervention in the form of a reduction in costs of this technology in the Technological Substitution pathway was made. As noted above, this intervention can be implemented in different ways into models. In both IMAGE and WITCH, this has been implemented as an improved learning rate for offshore wind and a reduction of the floor cost to the same level as onshore wind. These interventions can be regarded as mimicking a preference for offshore wind relative to onshore wind due to societal preferences for the former. In the Enertile model, offshore wind turbines were favoured by setting low interest rates thus lowering the effective costs approximately to the same level as onshore wind. In practice, such low interest rates may be initialised by government support programs, may consist of special state-aided loans to encourage investment, or may be the result of feed-in-tariffs. Low interest can also be interpreted as a high acceptance amongst private investors, who lower their profit expectations in favour of investing in an upcoming promising technology. Another intervention within Enertile to increase the preference for wind power consisted of increasing the availability of area for on- and offshore wind; for offshore, this just means that more area is available. For onshore wind, this mainly results in a higher concentration of highyield, often coastal sites.

In the Broader Regime Change pathway, only solar PV has been classified as typically belonging to such a pathway in both the UK and Germany. An important reason for this is that the German feed-in-tariff managed to reduce the price of the system, triggering much interest from households, consumers and local communities. Moreover, there is greater enthusiasm for decentralised PV installation across a broad range of actors, leading to social learning. This greatly accelerated the uptake and diffusion of solar PV. To emulate this increased interest for solar PV systems, IMAGE and WITCH introduced faster learning rates and lower floor costs that modify the PV costs. In Enertile, the land availability for all PV technologies was increased and the costs were decreased, following the same logic as for wind in the Technological Substitution pathway.

In addition to these interventions, based on Geels at al. (2015) and Rogge et al. (2015), we have made explicit choices in all models by excluding the use of the contested technologies CCS and nuclear in the Broader Regime Change pathway in the future, both of which are assumed to fit better in the Technological Substitution narrative. In the latter pathway, the future capacities of nuclear power are exogenously defined by country in Enertile: Countries without nuclear power plants 
Table 2

Scenario interventions in the two alternative pathways.

\begin{tabular}{|c|c|c|c|c|c|c|}
\hline & \multicolumn{3}{|c|}{ TECHNOLOGICAL SUBSTITUTION } & \multicolumn{3}{|c|}{ BROADER REGIME CHANGE } \\
\hline & IMAGE & WITCH & Enertile & IMAGE & WITCH & Enertile \\
\hline PV & & & $\begin{array}{l}\text { Relatively low } \\
\text { area availability } \\
\text { ( } 50 \% \text { less than in } \\
\text { "Broader regime } \\
\text { change") }\end{array}$ & $\begin{array}{l}\text { Grid } \\
\text { parity is } \\
\text { reached } \\
\text { for solar } \\
\text { PV by } \\
2040\end{array}$ & $\begin{array}{l}\text { Higher } \\
\text { learning rate } \\
\text { and lower } \\
\text { floor cost, } \\
\text { resulting in } \\
25 \% \text { lower } \\
\text { investment } \\
\text { cost on } \\
\text { average }\end{array}$ & $\begin{array}{l}25 \% \text { lower price } \\
\text { Relatively high } \\
\text { area availability } \\
\text { (twice as much } \\
\text { as in } \\
\text { "Technological } \\
\text { substitution") }\end{array}$ \\
\hline $\begin{array}{l}\text { Onshore } \\
\text { wind }\end{array}$ & & & $\begin{array}{l}\text { Area availability } \\
\text { settings allow for } \\
\text { a concentration at } \\
\text { the best sites }\end{array}$ & & & \\
\hline $\begin{array}{l}\text { Offshore } \\
\text { wind }\end{array}$ & $\begin{array}{c}\text { Price same } \\
\text { as } \\
\text { onshore }\end{array}$ & $\begin{array}{l}\text { Higher learning rate } \\
\text { and floor cost equal } \\
\text { to onshore wind, } \\
\text { resulting in a cost } \\
\text { alignment with } \\
\text { onshore wind after } \\
2050\end{array}$ & $\begin{array}{l}\text { Price same as } \\
\text { onshore; } 1 \% \\
\text { interest rate } \\
\text { High area } \\
\text { availability }\end{array}$ & & & $\begin{array}{l}\text { No support in } \\
\text { place }\end{array}$ \\
\hline $\begin{array}{l}\text { Nuclear } \\
\text { CCS }\end{array}$ & & & $\begin{array}{c}\text { Exogenously set } \\
\text { capacity } \\
\text { Bioenergy CCS } \\
\text { taken from IMAGE }\end{array}$ & \multicolumn{3}{|c|}{ No new capacity after 2010} \\
\hline
\end{tabular}

Social and behavioural change (demand, preferences)

Regulatory change (intervention, governance)

Technical change (acceleration)

Shock (shift away)

\begin{abstract}
${ }^{1}$ Learning rate is defined as the decrease in capital costs due to a doubling of cumulative installed capacity. In WITCH, this learning rate is applied on the capital costs of the different technologies. For solar power, TIMER applies the same method. For wind turbines, TIMER adopts a different approach. In order to capture knowledge spillovers between onshore and offshore wind turbines, two cost parts are identified: the turbine itself and an offshore cost markup. The turbine itself applies to both onshore and offshore wind, as the technology is regarded similar. The offshore markup only applies to offshore wind and equals additional costs required for installing an offshore wind turbine relative to an onshore wind turbine. In the Technological Substitution pathway, offshore wind is assumed to have no markup on floor costs (i.e. floor costs are $500 \mathrm{USD} / \mathrm{kW}$, which is the same as onshore wind). Both parts have a separate learning rate. The learning of the turbine part is influenced by both the installed cumulative capacity of onshore and offshore wind, while the offshore markup is only influenced by offshore wind installation. The learning rate of $17 \%$ on offshore wind in WITCH is approximated by IMAGE by setting the learning rate of offshore markup to $20 \%$ to compensate for the lower learning rate of wind turbines. For more information about the learning process, learning rates, and floor costs, the reader is referred to De Cian et al. (2012).
\end{abstract}

are assumed not to invest in nuclear energy and currently existing national phase-out policies are respected. For existing nuclear power plants and no phase-out policy, like France or the UK, we assumed decreasing investments into new power plants based on costs considerations.

At the demand side, several behavioural changes were assumed which lead to a change in electricity demand (van Sluisveld et al., this issue). In the Technological Substitution pathway, a 25\% purchasing subsidy on electric vehicles was implemented in IMAGE, while in WITCH the costs of electric vehicles were assumed to decline faster due to a $25 \%$ higher learning rate for batteries and a $50 \%$ increase in the growth rate of the efficiency of the engine. In the Broader Regime Change pathway, a higher vehicle occupancy rate was assumed in both models. Furthermore, a lower travel demand and vehicle ownership (directly in WITCH and via a decreased travel budget per person in IMAGE) and an increased preference for public transport were assumed. These measures lead to a higher electricity demand in the Technological Substitution pathway and a lower electricity demand in the Broader Regime Change pathway. Moreover, in IMAGE, there is a lower appliance electricity use due to more efficient use of appliances, phasing out tumbler dryers, and switching off standby modes. As in WITCH the household sector is not explicitly modelled, these behavioural changes were only considered in the IMAGE calculations.

\section{Results}

The results of our intermodel comparison scenario study are presented below, starting with the global scale, moving down to Europe as a whole and finally to national level. The degree of similarity between the model results provide an indication of the degree of flexibility in the 


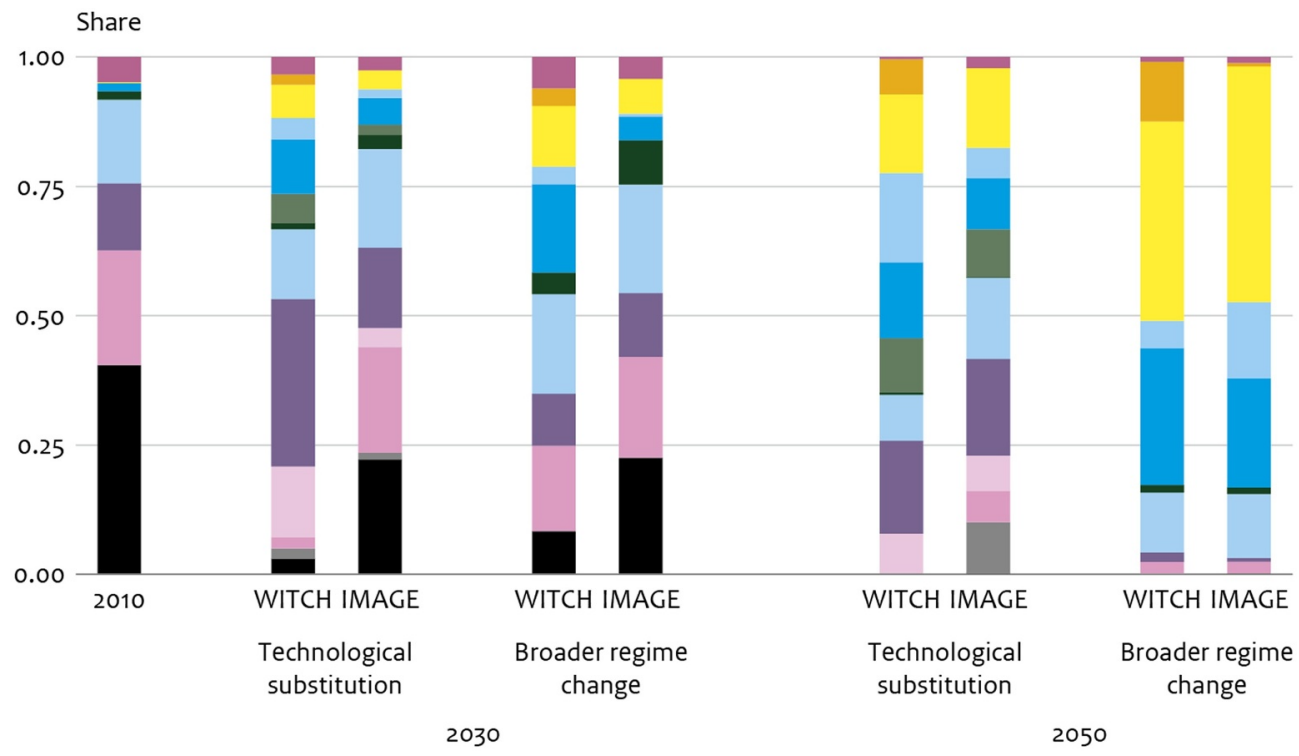

Fig. 1. Total global electricity generation by energy carrier. mitigation pathway: if different models lead to very differing outcomes, there could be relatively much flexibility in how the mitigation targets can be achieved and vice versa.

\subsection{Electricity system transition at the global scale}

Globally, $37 \%$ of electricity was generated by coal-fired power plants in 2016 , followed by gas (24\%), hydro (16\%), and nuclear (11\%) (OECD/IEA, 2017). In both mitigation scenarios, these shares change drastically, with coal being phased out by 2050 according to both IMAGE and WITCH, although the speed at which this occurs differs between the models (Fig. 1). WITCH projects a much faster phase out of coal in power production than IMAGE, made possible by a rapid expansion of nuclear power, wind onshore, solar PV, and CCS (both in combination with gas and biomass) in the Technological Substitution pathway and mainly solar PV and wind onshore in the Broader Regime Change pathway. By 2050, the shares of energy carriers are much more similar between IMAGE and WITCH than they are by 2030 .

Interestingly, the Technological Substitution pathway shows a much higher diversification in the electricity generation energy mix relative to today. In 2010 , almost $80 \%$ of electricity was generated by only three energy carriers (coal, gas, and hydro). In the Technological Substitution pathway, the five largest energy carriers together are responsible for less than $75 \%$ of total electricity generation by 2050 . The diversity in the Broader Regime Change pathway is less, as CCS and nuclear are either not allowed or phased out in these scenarios.

Surprisingly, IMAGE shows a higher share of offshore wind in the Broader Regime Change pathway than the Technological Substitution pathway, even though offshore wind is promoted in the latter pathway. The reason for this is that in the Broader Regime Change pathway, the share of offshore wind is higher as there is no competition with nuclear and CCS technologies. In WITCH, offshore wind has a smaller share in the Broader Regime Change pathway mainly because WITCH is more optimistic on the future cost developments of CSP. In the Technological Substitution pathway, offshore wind has to compete with more technologies than in the Broader Regime Change pathway. In many regions of the world, nuclear and CCS (both with fossil fuels and biomass) are still competitive with offshore even wind with the assumed higher learning rates and lower floor costs of the latter technology.

By 2050, the differences in energy mix are much larger between the two mitigation scenarios than between the models. In the Technological Substitution pathway, solar PV, onshore and offshore wind, BECCS, nuclear, hydro, and fossil fuels with CCS all have a significant share in the electricity mix according to both models. In the absence of CCS and nuclear in the Broader Regime Change pathway, more rapid upscaling of carbon-neutral alternatives and faster phase-out of fossil fuels are required. This implies that the role of gas as transition fuel is diminished, being phased out almost completely by 2050 . Instead, electricity is supplied for more than $80 \%$ by the VRE technologies solar and wind according to both models.

In this regard, it is important to stress the well-known system integration challenges related to such high penetration shares of VRE in the electricity mix. An option often discussed in this context are electricity storage facilities. Currently, pumped hydroelectric storages are the most common option for storing electricity large-scale. However, a wide-range of other options is discussed as well, including hydrogen, synthetic methane, compressed air and various types of batteries. In both IAMs, the required storage capacity is modelled quite simplistically, and do not fully capture the actual dynamics of the power system, especially in relationship with the role of grid: storage deployment is endogenously optimised in order to meet the aggregate flexibility and capacity requirements of the electric system. Hence, storage capacity grows in parallel with VRE growth in both models and in both scenarios. Global storage capacity reaches about $2.2 \mathrm{TW}$ (both in IMAGE and WITCH) by 2050 in the Broader Regime Change scenario, which is about $13 \%$ of the sum of wind and PV capacity. In the Technological Substitution pathway, less storage capacity is needed especially in IMAGE (0.4 TW in IMAGE and 1.8 TW in WITCH), which can be explained by the fact that IMAGE has a much lower share of VRE. As comparison, storage capacity in the baseline amounts to 0.22 TW in IMAGE and 0.4 TW in WITCH.

Grid expansion will also be important in both mitigation scenarios to allow a better renewable integration in the electricity system by pooling VRE plants over large geographical areas (Pietzcker et al., 2017), but this is not modelled in detail by the IAMs. For more information about system integration challenges related to high VRE shares, we refer to the recent ADVANCE multi-model exercise ${ }^{5}$ which focused on improving the modelling of VRE system integration in IAMs, in which both IMAGE and WITCH have participated. The reader is thus in particular referred to Pietzcker et al. (2017) and Luderer et al. (2017) for an overview, de Boer and van Vuuren (2017) for IMAGE, and Carrara and Marangoni (2017) for WITCH.

\footnotetext{
${ }^{5}$ http://www.fp7-advance.eu/
} 


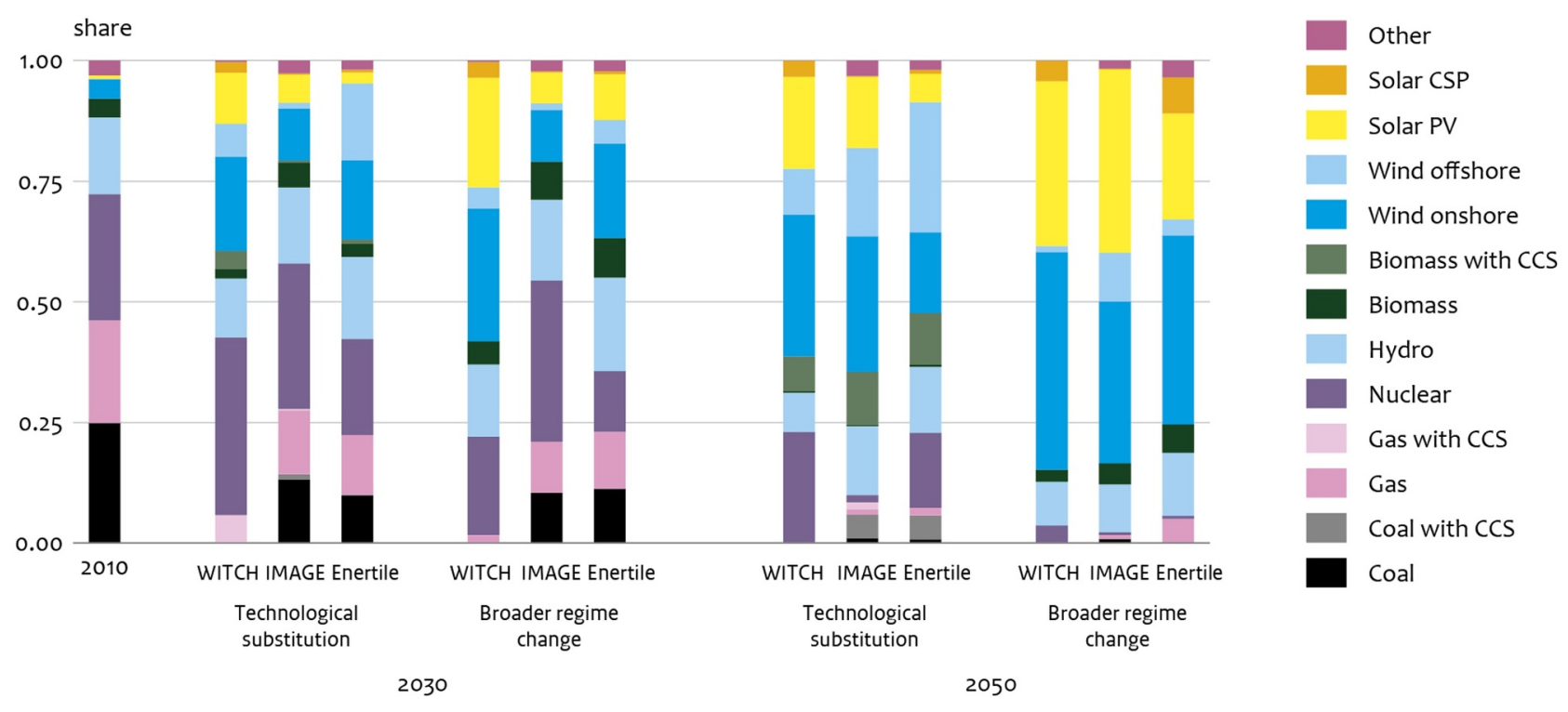

Fig. 2. Total EU electricity generation by energy carrier.

\subsection{Electricity system transition at European scale}

Compared to the global average, Europe had a lower share of coal and a higher share of nuclear in their electricity mix in 2010, the other shares being about the same (Fig. 2). In general, the European mitigation pathways show a similar trend as the global ones, with coal and gas being replaced by wind and solar. Also for Europe, WITCH projects a much faster phase out of coal in the electricity mix than IMAGE and Enertile. This is partly due to an already decreasing share of coal in the baseline in WITCH: without climate policy, the share of coal in European power supply is already reduced to $9 \%$ by 2050 in WITCH, whereas it stabilises around $26 \%$ in IMAGE.

For 2050, the three models show very similar results especially for the Broader Regime Change pathway. In the Technological Substitution pathway, IMAGE is the only model that shows a phase out of nuclear. . In Enertile, the capacity data for nuclear energy is defined exogenously to fit to the scenario's storyline (see Section 2.3). Without this predefinition, only the two nuclear reactors currently under construction would be running in 2050 . The results would then be very similar to the results of IMAGE The share of wind power increases strongly to $39-46 \%$ (range amongst the models and scenarios) by 2050, with a higher share of offshore in the Technological Substitution pathway. Enertile shows a higher share of offshore wind and a lower share of onshore wind compared to both global models, with both IMAGE and Enertile showing a larger share of offshore wind than WITCH. In the latter model, the cost assumptions described in Table 2 cannot make this technology fully competitive with onshore wind in Europe, contrary to the global scale.

CCS on fossil fuel-powered power plants does not play a major role in Europe in the Technological Substitution pathway (and by definition no role at all in the Broader Regime Change pathway). In Enertile, CCS is only used for lignite power plants, as CCS at coal and natural gas power plants does not become competitive. BECCS, however, becomes an important technology in both IMAGE and WITCH (note that Enertile is aligned with IMAGE with respect to BECCS), accounting for $7-11 \%$ of electricity generation by 2050 . These BECCS plants would have to be rather large, centralised power plants, either dedicated biomass power plants or used for co-firing in fossil fuel-fired power plants.

All models show for the Broader Regime Change pathway dominant roles for onshore wind and solar PV, and to a lesser extent hydropower. This is a consequence of less flexibility in technologies by phasing out nuclear power and excluding CCS from the energy mix. Onshore wind shows a much stronger development than offshore wind due to the lower costs of this technology. Note that this was not the case for IMAGE on the global level, implying that Europe has a relatively large potential of onshore wind and solar PV, so that the share of offshore is limited even if CCS are phased out completely. The phase-out of these technologies together with the lower price of solar PV clearly has an effect on the share of solar PV in the electricity mix: in the Broader Regime Change pathway the share of PV amounts to $22-38 \%$ in 2050 , while in the Technological Change pathway this is 6-19\%. Solar CSP also becomes part of the mix according to WITCH and Enertile. In the Broader Regime Change pathway, because of the higher share of the highly variable PV technology, natural gas still has a share of $5 \%$ according to Enertile, while in WITCH and IMAGE gas is almost completely phased out, since the VRE penetration is coupled with an implementation of storage. The vast majority of natural gas is used in highly efficient combined cycle natural gas plants which have low $\mathrm{CO}_{2}$ emissions compared to other conventional plants. The biomass used in this scenario also acts as moderate flexibility source. Considering the storyline of the Broader Regime Change pathway, the biomass would in this scenario be used primarily in decentralised, smaller (possibly combined heat and power) plants.

Due to the higher share of VRE in the Broader Regime Change pathway, storage of electricity is also more important in this pathway according to the IAMs IMAGE and WITCH. Like the global results, this is more pronounced in IMAGE than in WITCH. According to IMAGE, 140 GW of storage is needed in the Broader Regime Change pathway by 2050 , compared to $60 \mathrm{GW}$ in the Technological Substitution pathway and only $16 \mathrm{GW}$ in the baseline. In WITCH, the storage capacities are 343, 294, and $73 \mathrm{GW}$ respectively.

In the model Enertile, electricity storages are modelled in detail as a technological option on its own instead of being directly linked to other choices like in the IAMs IMAGE and WITCH. It takes the existing pumped hydro storages in each country into account, the installed capacity of which can be increased. Inflow, outflow, state of charge of the storages are represented and analysed for each hour of the year. In contrast to the IAMs, the model concludes that new storage facilities additional to the already existing pumped hydropower storages are neither necessary nor economic in the given scenarios. It manages to keep excess electricity needing to be curtailed to a minimum using mostly interregional balancing, i.e. by expanding and utilizing transmission grids. In the limited number of hours with now or low VRE, hydropower, biomass, or gas power plants are used to supply demand. 

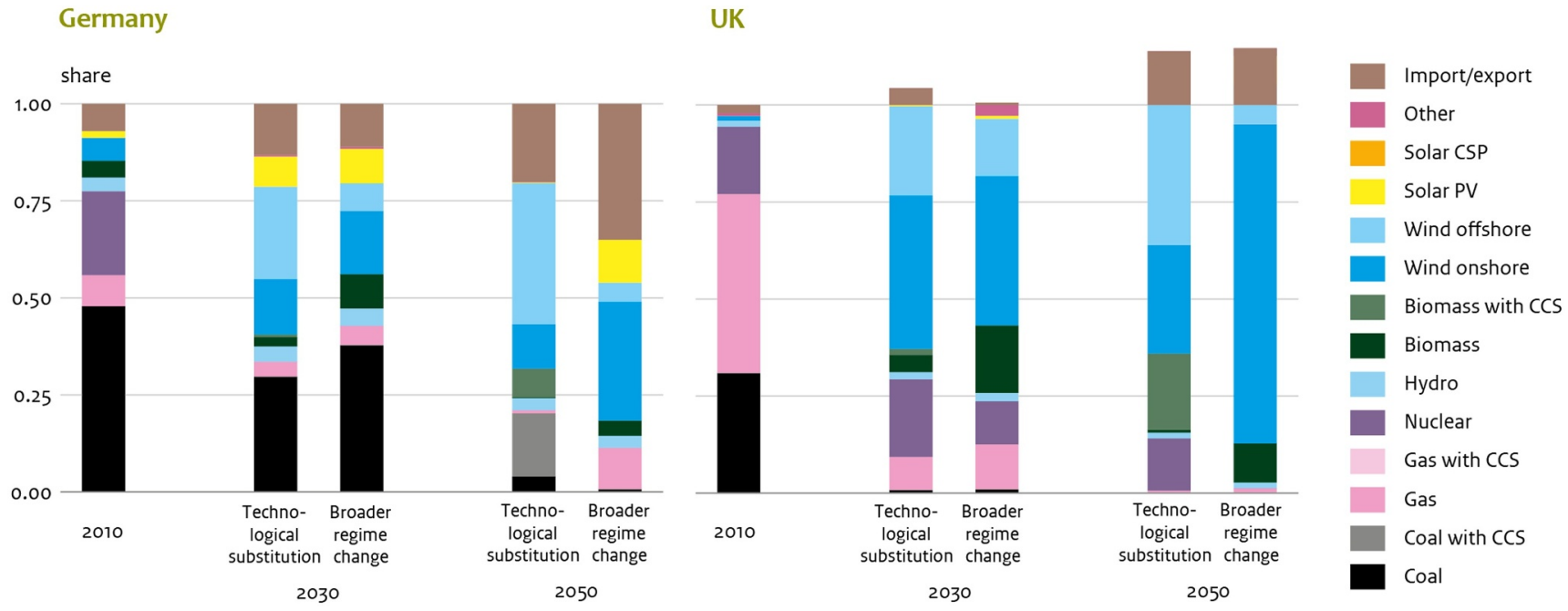

Fig. 3. Total electricity generation by energy carrier, Germany and the UK (Enertile).

The rather wide range of results reflects the fact that role of storages in the future electricity system is debated. On the one hand, they are an obvious solution for dealing with situations of over- and undersupply of generation from VRE. On the other hand, electricity storages compete with other flexibility options, such as demand flexibility. Counterintuitively, there is evidence that rising shares of VRE so far seem to have decreased the profitability of existing storage facilities (Barbour et al., 2016). This is to some extent driven by the growing length of periods of over- or undersupply. In a very windy week, for instance, typical storages are often completely charged after a day, meaning they are idle in the remaining time. Therefore, the storages face difficulties reaching the utilisation necessary for the high capital expenditures. Most research concludes that the high costs will remain a major challenge for the diffusion of storages (Kousksou et al., 2014; Rehman et al., 2015).

\subsection{Electricity system transition at country level}

In the UK, the extraordinary wind potential plays a crucial role in both the Technological Substitution and Broader Regime Change pathway (Fig. 3). With carbon prices above $50 \mathrm{EUR} / \mathrm{tCO}_{2} \mathrm{eq}$, many wind sites in the UK are the cheapest way of generating electricity in Europe at 0.05 EUR/kWh. However, the location of the UK makes it harder to balance fluctuations in renewable energy generation. Germany has much more neighbouring regions with different weather situations so that fluctuations in separate VRE technologies can be balanced more easily. However, except for some good sites in Northern Germany, wind power sites in Germany are only of average quality. The same is true for solar energy, for which the best sites are located in Southern Europe - which leads to export of electricity from Southern Europe to other European countries during the day. This leads to a relatively high import in Germany in the later decades in the Broader Regime Change.

As illustration, Fig. 4 shows the development of onshore wind turbines in the UK over time in the Technological Substitution pathway as resulting in Enertile. Each "tile" reflects an area of $7 \times 7 \mathrm{~km}$. The diffusion of onshore wind starts in the windiest, often coastal, areas of the UK. In the later decades, more and more inland sites are used - while keeping a certain distance to residential areas and nature protection areas. In 2050, a capacity of $77 \mathrm{GW}$ is installed, equal to about 15,500 wind turbines of $5 \mathrm{MW}$ each. The total offshore wind capacity is even larger. In the Broader Regime Change pathway, the total share of wind is even larger, with more onshore and less offshore wind. It is important to note that the high shares of wind in both the Technological Substitution and Broader Regime Change pathway require a strong expansion of the grid. This is especially relevant for the interconnectors to other countries, which are needed to balance the generation from renewable energy sources between weather zones all over Europe. This requires acceptance for the construction of new overhead lines.

In the Technological Substitution pathway, coal still plays a certain role in Germany due to the availability of CCS, while in the Broader Regime Change pathway, coal is pushed out of the system in the decarbonisation effort. The biomass, gas, and coal CCS power plants provide flexibility and reliable capacity. It should be noted, though, that the share of VRE still does not represent the potential maximum. The model is able to reach even higher VRE shares through increased demand side measure and grid expansion. Of the fossil plants and generation in Europe, a relatively high share is allocated to Germany, which acts as a "flexibility hub" in this scenario.

With regard to nuclear energy, Germany re-enacted its nuclear phase-out after the accident in Fukushima, so this technology is assumed not to be available in either the Technological Substitution or Broader Regime Change pathway after the decommissioning of the last reactor in 2022. The decline and the phase-out of nuclear energy is covered mostly by onshore wind and import in the Broader Regime Change pathway and by offshore wind in the Technological Substitution pathway. In the UK, the share of nuclear increases slightly in the first decades in the Technological Substitution pathway, after which it decreases, while it is replaced rapidly by wind in the Broader Regime Change pathway.

The abundance of good-quality renewable energy sites determines to a large degree how much a country imports or exports electricity; in our scenarios, the comparatively good wind sites turn the UK into a significant exporter of energy from 2030 onwards. This is in contrast with current trends: in 2010, the import-export balance of the UK was close to zero; since then, the country has increased its net imports, reaching 14.8 TWh in 2017 (UK Government, 2018). Compared to its electricity demand, Germany renewable energy potentials are below the European average. It is therefore more attractive to import a certain share of electricity from neighbouring countries than, for example, utilising mediocre wind sites in Southern Germany. In 2050, Germany imports approximately $20 \%$ of its electricity demand in the Technological Substitution pathway and $35 \%$ in the Broader Regime Change pathway.

While fossil fuels are practically phased out completely in the UK (except for a very small share of gas in Broader Regime Change pathway), in Germany there is still a significant share of coal $(4 \%$ in the Technological Substitution pathway) or gas (11\% in the Broader Regime Change pathway) in 2050. In this context, it is important to underscore that both scenarios, but especially the Broader Regime Change pathway, assume the existence of a pan-European power market. Germany acts as 


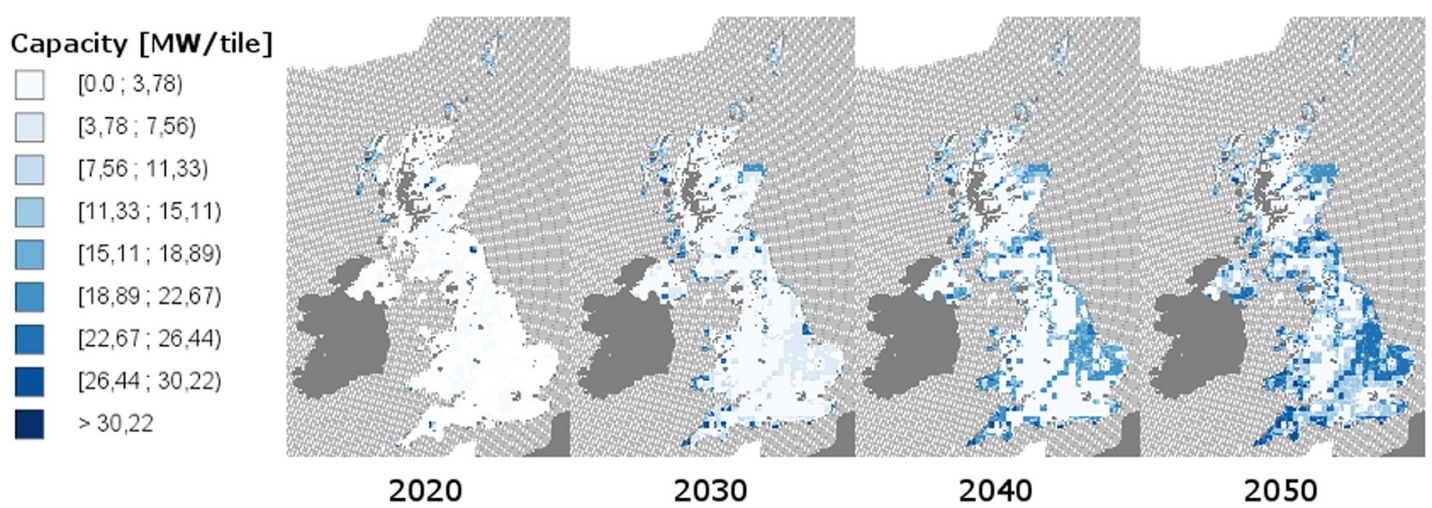

Fig. 4. Development of the spatial distribution of onshore wind turbines in the UK in the Technological Substitution pathway (Enertile).

a supplier of flexibility to the neighbouring countries, by concentrating on coal or natural gas power plants: in times of low feed-in from renewable energy, electricity from these power plants are exported to neighbouring countries. In the Technological Substitution pathway, conventional lignite generation shifts towards lignite with CCS from 2030 onwards in Germany.

Summarising, the overall picture is that conventional plants are replaced with renewable technologies. In both countries, by 2050 the main technology in the Technological Substitution pathway is offshore wind, followed by onshore wind and biomass CCS in the UK and coal with CCS and imports in Germany. In the Broader Regime Change pathway, the share of offshore wind is much smaller, and nuclear and CCS are replaced mainly by onshore wind in the UK and by onshore wind, solar PV and gas, and even more import in Germany.

\section{Discussion and conclusions}

In this paper, we have developed internally consistent scenarios from the global to national scale, systematically building on two contrasting mitigation storylines, focusing on the electricity sector. We have used MLP case studies on niche-innovations to characterise alternative transition pathways that go beyond cost considerations and account for broader changes in socio-technical components.

Combining quantitative modelling with qualitative storylines is not new. As discussed by McDowall (2014), broadly three approaches of doing so can be distinguished: i) using broad storylines to differentiate values of model parameters, ii) a detailed quantification of storylines, and iii) comparing and contrasting insights and dynamics produced in each method, using multiple iterations between modelling and scenario writing. The most well-known examples of approach i) are the construction of SRES (Nakicenovic et al., 2000) and SSP (O'Neill et al., 2014) scenarios. While our approach shares some characteristics of this approach, two major differences are that i) our scenarios are restricted by imposing a specific emission reduction target and ii) we have used more detailed insights from socio-technical transition studies (more specifically, from the MLP). Moreover, as explained in detail in Geels et al. (this issue), the modelling exercise presented here is part of a larger eight-step approach to construct socio-technical scenarios. This eight-step approach fits in category iii) of McDowall (2014): the quantitative scenarios presented in this study were informed by sociotechnical case studies on niche-innovations, while the quantitative scenarios provide the basis for creating the socio-technical scenarios. The socio-technical scenarios that have been developed based on our modelling exercise are discussed in Geels et al. (this issue) for the UK and in Rogge et al., al. (this issue) for Germany.

While the scenario results of the detailed electricity model Enertile were used for creating the socio-technical scenarios, we have linked this model with two global IAMs. An important advantage of linking IAMs to national or regional sector-specific models is that the results of these more specific models can be made consistent with a broader global transition scenario. For instance, scenario-dependant regional availability and prices of globally traded fuels, such as biomass, can be provided by the global IAM as input for the regional model.

While our main interest is in the relative importance of different technologies between models in different future narrative-based scenarios, it should be noted that WITCH projects a higher electricity demand than IMAGE, especially for Europe. This is partly due to more optimistic cost assumptions for nuclear and wind onshore by WITCH compared to IMAGE, as this leads to high renewable shares already without climate policy and therefore less need to reduce power generation in a climate mitigation scenario.

It is important to keep in mind that our two contrasting pathways reflect quite extreme scenarios with either all countries adopting a technological substitution pathway or a broader regime change pathway. While this has been done on purpose to show the range of outcomes, in reality it is unlikely that all countries adopt a similar strategy or even that within countries, a similar strategy is systematically pursued. In this sense, our scenarios should be interpreted as what-if scenarios and not as likely outcomes - although Rogge et al., al. (this issue) and Geels et al. (this issue) provide a narrative of how these futures could evolve.

Two important caveats of our exercise are i) we have coupled the European electricity model only with the results from the global IMAGE model and ii) we have based the narratives on case study analysis from only two countries. Regarding the first caveat, it should be mentioned that while this method provides insight in the differences in outcomes between alternative transition narratives on the country-level, it ignores uncertainties in future energy and $\mathrm{CO}_{2}$ prices and availability of biomass. To explore these uncertainties, outputs from different IAMs could be used to develop multiple scenarios with a sectoral model. Regarding the second caveat, the choice for selecting the UK and Germany has been made as current transitions in power supply in these countries show strong similarities with respectively a Technological Substitution and a Broader Regime Change pathway. Nevertheless, in other countries niche-innovations may show different transitions dynamics than in either the UK or in Germany. A more comprehensive set of case studies in different countries could provide a more robust picture of which niche innovations are usually targeted in different transition pathways.

Keeping in mind the above caveats, the following robust conclusions can be drawn from our analysis.

Taking into account social preferences in scenario development can have large impacts on the projected transition strategy. Large differences were found between the alternative mitigation pathways. This is especially the case for technologies which currently have a high momentum, but which based on costs only are not deployed on large scale in default cost-optimisation scenarios. The share of offshore wind, for instance, is marginal in scenarios which do not assume a 
preference factor for this technology, while adjusting the costs for this technology based on its current high momentum (more specifically, equalling the effective costs of offshore wind to those of onshore) could lead to a quarter of electricity being produced by offshore wind in Europe by 2050 , more than $35 \%$ in Germany and about $50 \%$ in the UK. In the UK, onshore wind plays an important role in both pathways, but with $28 \%$ in the Technological Substitution pathway and $82 \%$ in the Broader Regime pathway, also here large differences are projected. For solar PV, the sensitivity of cost assumptions on the projected share in the energy mix is similar. Globally, the share of solar PV is $15 \%$ under default cost assumptions for PV, but increases to $39-46 \%$ as a result of decreasing floor costs by only $12.5 \%$ and increasing the learning rate from $17 \%$ to $21 \%$. For Europe, similar differences are found. Given that solar PV costs have declined by about $80 \%$ between $2005-2014$ and since the 1970s, learning rates of $20 \%$ were observed (Kavlak et al., 2018), our differences in cost assumptions and learning rates between the pathways can be regarded as relatively small - but still have a very large impact on future energy system projections. This clearly show the flexibility in decarbonisation futures which can be explored by politicians. As such, using alternative transition narratives for scenario development provides policymakers with analytical instruments for testing alternative decarbonisation scenarios.

There are large differences in mitigation strategies between the global, European and country level. Globally, the range in the share of onshore wind across both the two IAMs and the two mitigation pathways is between $10 \%$ and $26 \%$ by 2050 , while for Europe, this is much higher at $28 \%$ to $45 \%$. The differences become even more distinct at country-level. In the UK, onshore and offshore wind power accounts for at least half of electricity generation by 2050 in the mitigation scenarios, followed by BECCS in the Technological Substitution pathway and biomass in the Broader Regime Change pathway. In Germany, fossil fuels continue to play an important role, especially coal with CCS in the Technological Substitution pathway and gas in the Broader Regime Change pathway. The relatively large role for gas in the latter pathway allows a very high share of variable renewables in this pathway. The above examples are clear indications that global scenario results cannot easily be translated to world regions, let alone countries.

In both mitigation pathways and according to all models, coal without CCS is almost completely phased out by 2050 . Both globally and in Europe, the share of coal is $1 \%$ or less by 2050, irrespective of the mitigation pathway or model used. Only in Germany, coal is still responsible for $4 \%$ of electricity production by 2050 in one of the mitigation pathways (Technological Substitution), compared to $39 \%$ in 2017 (Fraunhofer Institute, 2018). Globally, coal was still responsible for $37 \%$ of global electricity production in 2016, which implies a drastic restructuring of power supply.

A diversification of electricity supply takes place only in a Technology Substitution pathway. If no low-carbon electricity supply technologies are excluded, coal is being replaced by a diverse mix of technologies, leading to a future electricity system which is much more diverse than the current one. For instance, globally almost $80 \%$ of electricity was supplied by three energy carriers (coal, gas, and hydro) in 2010, whereas the three energy carriers with the largest share only represent about $50 \%$ of total supply by 2050 in the Technological Substitution pathway. Such a diversification in technologies in especially incumbent and technology-orientated pathways is in line with transitions literature (Geels et al., 2016; Geels and Penna, 2015). In the Broader Regime Change pathway, such a diversification does not take place.

Linking global IAMs with more detailed national sectoral models allows a reality check on global IAM results and illuminates the challenges on a more detailed geographical scale. The global IAMs used in our analysis show a high reliance on variable renewable technologies especially in a scenario in which CCS and nuclear are not implemented; by $2050,82-85 \%$ of electricity is being generated by solar and wind technologies in such scenarios (both globally and in
Europe). The more detailed sectoral model shows that a somewhat smaller share for Europe as a whole (72\%), but for some countries (like the UK) even higher shares are found. Such high shares stand up to a closer look at regional and hourly level, even without needing additional storage (beyond already existing pumped hydropower storages). Under the given assumptions in the detailed model, storage does not reach the utilisation rates necessary to compete with other options such as interregional balancing or using gas power plants. This provides an indication that the global IAMs may model required storage capacity too simplistically. Furthermore, the national sectoral model provides insight in where and how these transitions occur, underscoring the need for an integrated electricity market in Europe.

Linking detailed national sectoral models with global IAMs provides the global context for the national models. System boundaries prevent national models to have a detailed representation of global contexts. For instance, the availability of biomass and technology costs depends on future global developments. Global IAM scenarios provide insight in how different future scenarios affect such variables, which play a key role for national transition scenarios. As such, putting national scenarios in the context of global developments increases the credibility of such scenarios.

\section{Acknowledgements}

The research leading to these results has received funding from the European Union Seventh Framework Programme FP7/2007-2013 under grant agreement $\mathrm{n}^{\circ} 603942$ (PATHWAYS). SC acknowledges funding from the European Union's Horizon 2020 research and innovation programme under the Marie Sklodowska-Curie grant agreement $n^{\circ} 706330$ (MERCURY).

\section{Supplementary materials}

Supplementary material associated with this article can be found, in the online version, at doi:10.1016/j.techfore.2019.119882.

\section{References}

Barbour, E., Wilson, I.A.G., Radcliffe, J., Ding, Y., Li, Y., 2016. A review of pumped hydro energy storage development in significant international electricity markets. Renew. Sustain. Energy Rev. 61, 421-432.

Bosetti, V., Carraro, C., Galeotti, M., Massetti, E., Tavoni, M., WITCH: A World Induced Technical Change Hybrid Model, 2006. Hybrid modeling of energy-environment policies: reconciling bottom-up and top-down. Energy J. Special Issue 13-38.

Bouwman, A.F., T. Kram, K. Klein Goldewijk, Integrated modelling of global environmental change. an overview of image 2.4,2006. PBL Netherlands Environmental Assessment Agency, Bilthoven, The Netherlands.

Capros, P., Georgakopoulos, T., Mantzos, L., 1998. Economic and energy system implications of the European CO2 mitigation strategy for 2010: a model-based analysis Int. J. Environ. Pollution 10, 403-427.

Carrara, S., Marangoni, G., 2017. Including system integration of variable renewable energies in a constant elasticity of substitution framework: the case of the witch model. Energy Econ. 64, 612-626.

Clarke, L., Jiang, K., Akimoto, K., Babiker, M., Blanford, G., Fisher-Vanden, K., Hourcade, J.-.C., Krey, V., Kriegler, E., Löschel, A., McCollum, D., Paltsev, S., Rose, S., Shukla, P.R., Tavoni, M., Zwaan, B.C.C.v.d, Vuuren, D.P.v., Assessing Transformation Pathways, 2014. Climate Change 2014: Mitigation of Climate Change. Contribution of Working Group III to the Fifth Assessment Report of the Intergovernmental Panel On Climate Change. In: Edenhofer, O., Pichs-Madruga, R., Sokona, Y., Farahani, E., Kadner, S., Seyboth, K. (Eds.), Cambridge University Press, Cambridge, United Kingdom and New York, NY, USA.

Collins, S., Deane, J.P., Ó Gallachóir, B., 2017. Adding value to EU energy policy analysis using a multi-model approach with an EU-28 electricity dispatch model. Energy 130, $433-447$.

Danish Energy Agency, Energiscenarier frem mod 2020, 2035 og 2050, 2014. https://ens $\mathrm{dk} /$ sites/ens.dk/files/Energiklimapolitik/energiscenarier_-_analyse_2014_web.pdf.

de Boer, H.S.H.S., van Vuuren, D.D.P., 2017. Representation of variable renewable energy sources in TIMER, an aggregated energy system simulation model. Energy Econ. 64, 600-611.

De Cian, E., Bosetti, V., Tavoni, M., 2012. Technology innovation and diffusion in "less than ideal" climate policies: an assessment with the witch model. Clim Change 114, $121-143$.

De Cian, E., Dasgupta, S., Hof, A.F., van Sluisveld, M.A.E., Köhler, J., Pfluger, B., van Vuuren, D.P., Actors, 2017. Decision-making, and institutions in quantitative system 
modelling, HYPERLINK $\backslash 1$ "S0040-1625(19)31801-3" Technol. Forecast. Soc. Change.

De Cian, E., Tavoni, M., 2012. Do technology externalities justify restrictions on emission permit trading? Resour. Eng. Econ. 34, 624-646.

Deane, J.P., Chiodi, A., Gargiulo, M., Ó Gallachóir, B.P., 2012. Soft-linking of a power systems model to an energy systems model. Energy 42, 303-312.

Deetman, S., Hof, A.F., van Vuuren, D.P., 2015. Deep CO2 emission reductions in a global bottom-up model approach. Clim. Policy 15, 253-271.

Dellink, R., Chateau, J., Lanzi, E., Magné, B., 2017. Long-term economic growth projections in the shared socioeconomic pathways. Global Environ. Change 42, 200-214.

Després, J., Mima, S., Kitous, A., Criqui, P., Hadjsaid, N., Noirot, I., 2017. Storage as a flexibility option in power systems with high shares of variable renewable energy sources: a POLES-based analysis. Energy Econ. 64, 638-650.

Drouet, L., A. Haurie, M. Labriet, P. Thalmann, M. Vielle, L. Viguier, A coupled bottomup/top-down model for GHG abatement scenarios in the swiss housing sector, 2005. in: Energy and Environment, pp. 27-61.

E3MLab, PRIMES model. version 6, 2016-2017. detailed model description, 2016. E3MLab. http://www.e3mlab.ntua.gr/e3mlab/PRIMES\%20Manual/The\%20PRIMES \%20MODEL\%202016-7.pdf.

Emmerling, J., L. Drouet, L.A. Reis, M. Bevione, L. Berger, V. Bosetti, S. Carrara, E. De Cian, G.D.M. D'Aertrycke, T. Longden, M. Malpede, G. Marangoni, F. Sferra, M. Tavoni, J. Witajewski-Baltvilks, P. Havlik, The witch 2016 model - Documentation and implementation of the shared socioeconomic pathways, 2016. FEEM WP 2016 042.

European Commission, A roadmap for moving to a competitive low carbon economy in 2050, 2011. Brussels.

Fraunhofer Institute, Power generation in Germany - assessment of 2017, 2018. https:// www.ise.fraunhofer.de/content/dam/ise/en/documents/publications/studies/ Stromerzeugung_2017_e.pdf.

Geels, F.W., Socio-technical transitions to sustainability: a review of criticisms and elaborations of the multi-level perspective, 2019. Current Opinion in Environmental Sustainability.

Geels, F.W., 2002. Technological transitions as evolutionary reconfiguration processes: a multi-level perspective and a case-study. Res. Policy 31, 1257-1274.

Geels, F.W., Kern, F., Fuchs, G., Hinderer, N., Kungl, G., Mylan, J., Neukirch, M. Wassermann, S., 2016. The enactment of socio-technical transition pathways: a reformulated typology and a comparative multi-level analysis of the German and UK low-carbon electricity transitions (1990-2014). Res. Policy 45, 896-913.

Geels, F.W., A. McMeekin, M. Hodson, Analysis of green niche-innovations and their momentum in the two pathways. country report 2: green niche-innovations in the UK electricity system, 2015. http://www.pathways-project.eu/output.

Geels, F.W., McMeekin, A., Pfluger, B., 2018. Socio-technical scenarios as a methodological tool to explore social and political feasibility in low-carbon transitions: bridging computer models and the multi-level perspective in UK electricity generation (2010-2050), HYPERLINK \l "S0040-1625(19)31801-3" Technol. Forecast. Soc. Change.

Geels, F.W., Penna, C.C.R., 2015. Societal problems and industry reorientation: elaborating the dialectic issue lifecycle (DILC) model and a case study of car safety in the USA (1900-1995). Res. Policy 44, 67-82.

Geels, F.W., Schot, J.W., 2007. Typology of sociotechnical transition pathways. Res. Policy 36, 399-417.

Grandjean, A., E. Blanchet, E. Finidori, Étude des 4 tranjectoires du DNTE - Une vision pédagogique des 4 trajectoires étudiées dans le cadre de débat national sur la transition energétique, 2014. http://www.carbone4.com/wp-content/uploads/2016/08/ Etude_Trajectoires_DNTE_C4.pdf.

IPCC, 2014. Summary for policymakers. In: Edenhofer, O., Pichs-Madruga, R., Sokona, Y., Farahani, E., Kadner, S., Seyboth, K. (Eds.), Climate Change 2014, Mitigation of Climate Change. Contribution of Working Group III to the Fifth Assessment Report of the Intergovernmental Panel On Climate Change. Cambridge University Press, Cambridge, United Kingdom and New York, NY, USA.

Jochem, E., W. Schade, ADAM 2-degree scenario for Europe - policies and impacts, 2009. http://www.astra-model.eu/doc/ADAM.pdf.

Kavlak, G., McNerney, J., Trancik, J.E., 2018. Evaluating the causes of cost reduction in photovoltaic modules. Energy Policy 123, 700-710.

Kc, S., Lutz, W., 2017. The human core of the shared socioeconomic pathways: population scenarios by age, sex and level of education for all countries to 2100. Global Environ. Change 42, 181-192.

Kousksou, T., Bruel, P., Jamil, A., El Rhafiki, T., Zeraouli, Y., 2014. Energy storage: applications and challenges. Solar Energy Mater. Solar Cells 120, 59-80.

Kriegler, E., Weyant, J.P., Blanford, G.J., Krey, V., Clarke, L., Edmonds, J., Fawcett, A. Luderer, G., Riahi, K., Richels, R., Rose, S.K., Tavoni, M., van Vuuren, D.P., 2014. The role of technology for achieving climate policy objectives: overview of the EMF 27 study on global technology and climate policy strategies. Clim. Change 123, 353-367.

Li, F.G.N., Trutnevyte, E., 2017. Investment appraisal of cost-optimal and near-optimal pathways for the UK electricity sector transition to 2050. Appl. Energy 189, 89-109.

Luderer, G., Pietzcker, R.C., Carrara, S., de Boer, H.S., Fujimori, S, Johnson, N., Mima, S., Arent, D., 2017. Assessment of wind and solar power in global low-carbon energy scenarios: An introduction, 2017. Energy Econ. 64, 542-551.

McDowall, W., 2014. Exploring possible transition pathways for hydrogen energy: a hybrid approach using socio-technical scenarios and energy system modelling. Futures 63, 1-14.

McGlade, C., Pye, S., Watson, J., Bradshaw, M., Ekins, P., 2016. The Future Role of Natural Gas in the UK, Research Report. UK Energy Research Centre, London.

Meinshausen, M., Raper, S.C.B., Wigley, T.M.L., 2011. Emulating coupled atmosphereocean and carbon cycle models with a simpler model, MAGICC6 - Part 1: model description and calibration. Atmos. Chem. Phys. 11, 1417-1456.
Nakicenovic, N., Alcamo, J., Davis, G., de Vries, B., Fenhann, J., Gaffin, S., Gregory, K., Grübler, A., Jung, T.Y., Kram, T., Emilio la Rovere, E, Michaelis, L., Mori, S., Morita, T., Pepper, W., Pitcher, H., Price, L., Riahi, K., Roehrl, A., Rogner, H., Sankovski, A., Schlesinger, M., Shukla, P., Smith, S., Swart, R., van Rooyen, S., Victor, N., Dadi, Z., 2000. IPCC Special Reports: Special Report On Emissions Scenarios. Cambridge University Press, Cambridge, UK.

O'Neill, B.C., Kriegler, E., Ebi, K.L., Kemp-Benedict, E., Riahi, K., Rothman, D.S., van Ruijven, B.J., van Vuuren, D.P., Birkmann, J., Kok, K., Levy, M., Solecki, W., 2014. The roads ahead: narratives for shared socioeconomic pathways describing world futures in the 21st century. Glob. Environ. Change.

O'Neill, B., Kriegler, E., Riahi, K., Ebi, K., Hallegatte, S., Carter, T., Mathur, R., van Vuuren, D., 2014. A new scenario framework for climate change research: the concept of shared socioeconomic pathways. Clim. Change 122, 387-400.

OECD/IEA, World energy outlook 2017, 2017.

Öko-Institut, F. ISI, 2016. Klimaschutzszenario 2050: zusammenfassung des 2. endberichts studie im auftrag des bundesministeriums für umwelt, naturschutz. Bau und Reaktorsicherheit. https://www.oeko.de/oekodoc/2451/2015-608-de.pdf.

Pfluger, B., 2014. Assessment of least-cost pathways for decarbonising Europe's power supply a model-based long-term scenario analysis accounting for the characteristics of renewable energies. KIT Scientific Publishing file:///C:/Users/Andries/ Downloads/978-3-7315-0133-6.pdf.

Pietzcker, R.C., Ueckerdt, F., Carrara, S., de Boer, H.S., Després, J., Fujimori, S., Johnson, N., Kitous, A., Scholz, Y., Sullivan, P., Luderer, G., 2017. System integration of wind and solar power in integrated assessment models: a cross-model evaluation of new approaches. Energy Econ. 64, 583-599.

Rehman, S., Al-Hadhrami, L.M., Alam, M.M., 2015. Pumped hydro energy storage system: a technological review. Renew. Sustain. Energy Rev. 44, 586-598.

Rogge, K., Analysis of green niche-innovations and their momentum in the two pathways. country report 1: green niche-innovations in the German electricity system, 2015. http://www.pathways-project.eu/output.

Rogge, K.S., Pfluger, B., Geels, F.W., 2017. Transformative policy mixes in socio-technical scenarios: the case of the low-carbon transition of the German electricity system (2010-2050), HYPERLINK $\backslash 1$ "S0040-1625(19)31801-3" Technol. Forecast. Soc. Change.

Staub-Kaminski, I., Zimmer, A., Jakob, M., Marschinski, R., 2014. Climate policy in practice: a typology of obstacles and implications for integrated assessment modeling. Clim. Change Econ. 5, 1440004.

Stehfest, E., van Vuuren, D., Kram, T., Bouwman, L., Alkemade, R., Bakkenes, M., Biemans, H., Bouwman, A., den Elzen, M., Janse, J., Lucas, P., van Minnen, J., Müller, M., Prins, A., 2014. Integrated Assessment of Global Environmental Change with IMAGE 3.0. Model description and Policy Applications. PBL Netherlands Environmental Assessment Agency, The Hague.

Trutnevyte, E., 2016. Does cost optimization approximate the real-world energy transition? Energy 106, 182-193.

Trutnevyte, E., Barton, J., O'Grady, T., Ogunkunle, D., Pudjianto, D., Robertson, E., 2014. Linking a storyline with multiple models: a cross-scale study of the UK power system transition. Technol. Forecast. Soc. Change 89, 26-42.

UK Government, 2018. Digest of United Kingdom energy statistics 2018. Department for Business, Energy and Industrial Strategy (BEIS). https://www.gov.uk/government/ collections/digest-of-uk-energy-statistics-dukes.

UNFCCC, 2015. FCCC/CP/2015/L.9/Rev.1: Adoption of the Paris Agreement. UNFCCC, Paris, France.

van Sluisveld, M.A.E., Hof, A.F., Carrara, S., Geels, F., Nilsson, M., Rogge, K., Turnheim, B., van Vuuren, D.P., 2019. Aligning integrated assessment modelling with sociotechnical transition insights: an application to low-carbon energy scenario analysis in Europe, HYPERLINK $\backslash 1$ "S0040-1625(19)31801-3" Technol. Forecast. Soc. Change.

van Vuuren, D.P., Stehfest, E., den Elzen, M.G.J., Kram, T., van Vliet, J., Deetman, S., Isaac, M., Klein Goldewijk, K., Hof, A.F., Beltran, A.M., Oostenrijk, R., van Ruijven, B., 2011. RCP2.6: exploring the possibility to keep global mean temperature increase below $2{ }^{\circ} \mathrm{C}$. Clim. Change 109, 95-116.

Weyant, J., Knopf, B., De Cian, E., Keppo, I., van Vuuren, D.P., 2013. Introduction the the EMF28 study on scenarios for transforming the European energy system. Clim. Change Econ. 04, 1302001.

Andries Hof is senior researcher at PBL Netherlands Environmental Assessment Agency and guest researcher at the Faculty of Geosciences, Utrecht University. He holds a university degree in economics (1999), after which he conducted research at several institutes in the Netherlands, Germany, and the US. In 2007, he started working on a EU research project about mitigation and adaptation strategies for climate change policy at $\mathrm{PBL}$ and received his $\mathrm{PhD}$ with this topic in 2010. Andries has authored more than 50 publications in peer-reviewed journals.

Samuel Carrara is researcher at Fondazione Eni Enrico Mattei (FEEM), Milan, Italy. Hismain research interests include renewable energies, sustainable development, energy policies, climate and energy economics, advanced energy systems and transportation. In early 2016 he was granted a Marie Skłodowska-Curie Global Fellowship by the European Commission, which is characterised by an outgoing phase as a visiting scholar at the University of California, Berkeley in 2017 and a return phase at FEEM in 2018.

Enrica De Cian is a senior researcher at Fondazione Eni Enrico Mattei (FEEM). She obtained the $\mathrm{PhD}$ in Economics and Organization from Ca' Foscari University of Venice in 2008. In 2012 she obtained a Marie Curie Research Fellowship and in 2012-2013 she was research scholar at the Department of Earth and Environment, Boston University, USA Her research interests include integrated assessment modelling, economics of adaptation, climate change impacts, climate change policies, technological change. 
Benjamin Pfluger joined the Fraunhofer Institute for Systems and Innovation Research in 2008, first in the Competence centre Energy Policy and Energy Systems and since 2012 in the Competence centre Energy Policy and Energy Markets. He obtained his PhD in 2014 on the assessment of least-cost pathways for decarbonising Europe's power supply, for which he developed the Enertile model which optimises capacity expansion and hourly despatch of both conventional and renewable power generation, transmission grids and storage facilities on hourly basis. His-work focuses on renewable energies and their promotion and the modelling of energy systems and markets.

Mariësse van Sluisveld is a researcher at PBL Netherlands Environmental Assessment Agency. Her expertise is in integrated assessment modelling and scenario development. Her current work focuses on alternative transition pathways that meet long-term climate policy targets, on which she obtained her $\mathrm{PhD}$ in 2017. Her main interests are in the fields of climate policy, lifestyle change and material efficiency. She holds a $\mathrm{PhD}$ degree in Sustainable Development with a major in Energy and Resources from Utrecht University.
Harmen Sytze de Boer is a researcher at PBL Netherlands Environmental Assessment Agency. Harmen Sytze holds a master degree in Energy and Environmental Sciences obtained at the University of Groningen (2012) and a bachelor degree in Mechanical Engineering obtained at the Hanzehogeschool Groningen (2010). His-master thesis research focused on the effects of applying different large scale energy storage systems in the Dutch electricity system. His-current work focuses on system integration, path dependencies, and resource constraints in the energy system.

Detlef van Vuuren is senior researcher at PBL Netherlands Environmental Assessmen Agency and a professor in Integrated Assessment of Global Environmental Change at the Faculty of Geosciences, Utrecht University. His-research concentrates on response strategies to global environmental problems using integrated assessment models. Detlef van Vuuren had a coordinating role in the development of the Representative Concentration Pathways (RCPs) now used in IPCC assessments. Detlef van Vuuren has participated as (Coordinating) Lead Author in various assessments such the Millennium Ecosystem Assessment, UNEP's Global Environmental Outlook, and the OECD Environmental Outlook. He has published more than 230 articles in refereed journals. 